\title{
A Pamphlet Method for Research Libraries
}

Where should I put that wonderful tame lion? Under "Animals Wild?" Certainly, or, perhaps under "African Beasts of Prey?" No ... let's see... that lion wasn't in a zoo, nor was he in Africa. He was in some kind of carnival or circus. That's it! "Circus." Of course, I could have cross-filed it under those various categories. It was terrific! So I decided: "I'll just let the beautiful lion lie here on top temporarily. I'll arrange everything later. In the meantime it can stay right here. On some rainy Saturday night I'll reorganize the whole collection."-George Grosz's Autobiography

$\mathrm{T}$ HE EXTENT and nature of pamphlet treatment by the research library should be determined by the following factors: the cost of processing and maintaining in relation to the importance of the material for that library, and the peculiarities of physical makeup and utilization which dictate specific techniques.

Whether or not pamphlets are important in such a library can be decided on the basis of their possession of certain values: those of reference and research. The modernity and reliability of the specific pamphlet will determine if its factual data, its hypotheses, opinions, and arguments will be utilized as the author intended, or for secondary artifactual purposes.

An empirical survey of thousands of unanalyzed pamphlets in the Hopkins Transportation Library at Stanford University, which cover a period of forty years, revealed that their values were generally parallel with those of the book collection in type but on a lower critical level. The propagandistic broadside of the early pamphleteer has been supplanted to some extent by the more subtle "public relations" product of organizational derivation. The nonpartisan current events brochure is a recent developing phenomenon. The intent of most pamphlets, seemingly, is to convince, to sway, whether by manipulation of emotional stimuli or by mobilization of logical argument on an elementary plane.

It is apparent that pamphlets are not valuable enough, barring an occasional exception, to accord the full elaborate treatment of conventional cataloging. To most writers on the subject, this means that a dichotomy is set up: full cataloging or none. ${ }^{1}$ Our purpose is to inquire what happens to this neat division of possibilities if, by using unorthodox methods, a library is able to achieve nearly all the bibliographical objectives of complete cataloging and at the same time to process seven to ten pamphlets at a cost comparable to that of preparing one book.

There are two alternative methods of making pamphlets available. The first might be called the method of arrangement, wherein the location of the pamphlet within

${ }^{1}$ One such example is the following: "If the informa. tion to be obtained from pamphlets is of a general character, and the entire collection is used to furnish material on a topic but not specific items on that topic, the Information File, or the shelved pamphlet collection is the best means of handling them. If on the other hand, these pamphlets are to be used for research pur. poses, and to corroborate and supply specific data or specific topics, the best process is to catalog them and shelve them with the book collection." Smith, Mrs. Margaret G. "Solving the Problems of a Pamphlet Collection." Special Libraries 28:77, March r937. 
a group of pamphlets or other materials is employed as its single finding device; the other utilizes arrangement as one of several coordinate factors.

In the first alternative method, the position of the individual unit within the system may incorporate several steps of subordination by the use of tabs, markers, colors, or numbers, but its basis is defined as self-indexing and no auxiliary aids are used. Examples are: vertical files divided primarily by subject and secondarily by author; pamphlets shelved into a formal classification scheme by number and author subdivisions, or by this classification separately; pamphlet box collections divided downward by subject and author, or by date, subject, and author, or by any other sequence of filing. The characteristic of this method is that there is one primary avenue of approach to the pamphlet, and in each case it is a physical approach. The secondary devolution is always dependent on the main principle of division. Finding a pamphlet by author in a vertical file divided initially into subjects, for instance, is dependent on first knowing or guessing the specific subject of the pamphlet.

How efficient is this bibliographical method of arrangement in terms of the needs of the research worker? There is a queer inverted logic at work in the language of those who defend it. The usual explanation begins by finding it a necessary if unfortunate departure from fuller indexing techniques. The expedient forced into being then gradually achieves excellence in its own right and finally theoretical superiority. The vertical file is the most popular exemplification of the "arrangement" principle; and here are some ideas from proponents of the pamphlet file expressed by Amerine, ${ }^{2}$

2 Amerine, Elizabeth. "The Clipping and Pamphlet File." Wilson Bulletin 9:113-19, November 1934.
Condit, ${ }^{3}$ Dickey, ${ }^{4}$ Fairfax, ${ }^{5}$ Hall, ${ }^{6}$ and Ireland: ${ }^{7}$ (a) a dictionary arrangement is possible, (b) the vertical file has greater simplicity, (c) it is convenient to use, (d) it is a time-saver, (e) it is a space-saver.

\section{Examination of Concepts}

A detailed examination of these concepts does not support the combined premise, argument, and conclusion which each incorporates.

(a) A dictionary arrangement is possible. A dictionary arrangement of what? Presumably, an arrangement in alphabetical sequence of subject headings typed on the tabs of pamphlet folders. As such, it will be obvious that this dictionary arrangement has the same perplexing characteristics as an alphabet of subject headings on cards or in printed indexes and that it has fewer helpful ones, since the individual pamphlet can be placed in only one folder. This is not to say that the subject approach is not central in creating accessibility to pamphlet material. The question is, for the research library, whether this limited subject approach is adequate in itself.

(b) The pamphlet file has greater simplicity. The indefinite comparative of this slogan, like those in cigarette ads, has emotional appeal hard to beat down. However, an analysis of the context usually reveals that it is "simpler" than a grouping by class number, often a Dewey scheme, without additional finding aids. ${ }^{8}$ Since most people cannot know classification notation in detail by memory, the comparison

\footnotetext{
Cordit, Lester. A Pamphlet about Pamphlets. Chicago, University of Chicago Press, r939.

1 Dickey, Philena A. The Care of Pamphlets and Clippings in Libraries. White Plains, N.Y., H. W. Wilson Co., r917.

Fairfax, Virginia. Pamphlets and Clippings in a Business Library. San Francisco, r92r.

"Hall, Wilmer L. "Arrangement and Disposition of Pamphlets and Clippings." Virginia State Library Bulletin, v. 15, no. 1, 1924 .

${ }^{7}$ Ireland, Mrs. Norma O. The Pamphlet File in School, College, and Public Libraries. Boston, F. W. Faxon Co., 1937.

8 Smith, op. cit., p. 77.
} 
hardly seems fair. Nevertheless, the simplicity of the pamphlet file is largely illusionary. It is not sufficient to alphabet a group of folders. There are all the usual problems attendant in the locating of material: (I) If the subject is complex or if there is more than one subject in a pamphlet, the problem is that of assigning the "proper" heading, and any choice may prove invalid for a great number of users. The card subject file, it will be recalled, can place an item under many headings. ${ }^{9}$

If there are variations of heading, inversions, etc., cross references are needed. (3) If the file becomes large enough, the confusion of places to look in an alphabetical listing of subjects (which does not juxtapose similar subjects) can become so great that it will render the instrument incapable of use in its so-called "self-indexing" state. That this confusion is not altogether a theoretical extension of a priori reasoning may be tested by examining an article by Amerine ${ }^{10}$ and the subsequent series of letters and retorts published in the same volume of the Wilson Bulletin. Miss Amerine makes the rather wistful observation that the pamphlet file will not work without auxiliary aids. She recommends a card catalog of headings and references to supplement the vertical file. "One quickly sees the value of a catalog by noting these references, and how it would be impossible to serve effciently without one," she writes. Later in the article she advocates making a few title cards-"For pamphlets which we believe would be asked for by title." Her correspondents assured her that cross references could be put directly into the vertical file.

\footnotetext{
9 Thus Hall finds that "the content of an item, which ordinarily would be covered in cataloging by the several subject headings which apply, may indicate a compromise in assigning the one subject heading for filing as there is no practicable means of bringing out each sub. ject unless the item is fully cataloged." OP. cit., p. 8-9. The italics are ours, and this paper is a commentary, in a sense, on the matter italicized. a sense, on
$10 \mathrm{OP}$. cit.
}

They did not attack the more basic questions. The central point remains: the vertical file is not the simple instrument it appears to be.

\section{Convenience}

(c) It is convenient to use. If the file is adequately cross-referenced and sufficiently small, it may be convenient to use if the approach is from subject only and vague enough to be satisfied with a partial exhaustion of resources of the file. If a research worker is looking for a specific pamphlet or a subject varying from the subject heading assigned or if he is interested in seeing the adjunctive book literature at the same time, it cannot be called a convenient tool, for him.

(d) It is a time-saver. Depending on how many aids are developed to render it convenient to use, it wastes the time of the researcher in varying degrees. For the staff, its time-saving qualities must be balanced against its usefulness and the cost of other methods.

(e) It is a space-saver. The vertical file does not save space in the research library. It makes inefficient use of floor space in comparison with ordinary stack shelving. In a research library where the collection of ephemera is growing constantly and cannot be pruned in the cavalier manner common to public library files, the space problem of batteries of steel drawers, and their costs, are matters of some concern to librarians.

It may be objected that the arguments here refuted are those constructed by public librarians whose use of pamphlet literature is less precise than that of research librarians; however, a more fundamental defense of the "self-indexing" principle for pamphlets, and one which is concerned only with research libraries, can be found em- 
bedded in a brilliant paper by John Lund. ${ }^{11}$ It is desirable to quote at length:

Since this type of material (pamphlets and similar items) will not be listed in the authortitle catalog, it can go directly to the reference librarian who can supervise its shelving in a special room or section of the stack and make whatever lists or indexes may be necessary. In time these collections will develop into what may be called research collections and will include a great deal of material that belongs much more properly in such a collection than in the general stacks. For this type of material, then, the reference librarian, with the help of his shelf arrangement, actually takes the place of the subject catalog. And it is quite probable that he will be of more help to research workers than any subject catalog could ever be.

This argument begins with the assumption that pamphlet material is overwhelmingly "research" in nature; "it is material that is not referred to by any specific reference and which has lost its originally intended significance and is important for some other reason." This peculiar nature (in passing, it might be pointed out that the two supposed ingredients of research material do not necessarily appear together) is given as justification for separating it from other "stack" materials, for arranging it by subject, and for working from the arrangement without auxiliary aids (an adequate description of the "self-indexing" method). No subject cataloging is contemplated although separate lists and "indexes" are allowed. (For the word "indexes" we read "bibliographies," since if what are meant are actually indexes-detailed subject, author, title, or added entry indexes-then the entire thesis is reversed and the resulting treatment is approximately that of conventional cataloging.)

There are several criticisms which can

11 Lund, John J. "The Cataloging Process in the University Library: A Proposal for Reorganization.' College and Research Libraries 3:212-18, June 1942. be made of these ideas. The pragmatic approach to pamphlet literature, in the first place, does not justify its being called exclusively "research" material in the sense Mr. Lund indicates. Even assuming that it is predominantly of this character, however, it does not follow that particularized reference will not be made to it. There is an important and valid distinction between going to a pamphlet for a certain fact (which, let us say, is now discredited) and going to that pamphlet by author citation or title citation or variegated subject approach in order to utilize the discredited fact in research. It is crucial that, regardless of the ultimate intent of the scholar, the approaches to written sources remain approximately the same. The object of a modern researcher in examining a pamphlet on a system of control for flying machines by James Means may not be to adopt the principles therein expounded as a scientific basis for experiment, but he will be grateful for all specific approaches which guide him to it.

The fact of the matter is that, although pamphlet material is not primarily reference material, the unit pamphlet may be designated or "referred to." The fallacy would seem to be that of confusing the nature of the instrument with the nature of its employment. In view of the enormous masses of source materials now pouring into circulatory channels, it is not evident logic to hold that a reference librarian with the aid of a shelf arrangement and bibliographies can offer satisfactory assistance to scholars who are scarcely able to devote time to a leisurely browsing for evidence or point of view. The British Ministry of Supply found it imperative to set up, by machine methods, a subject index concurrent with their descriptive cataloging process in dealing with the flood quantities of German research material in aeronautics which came 
out of the war. It seems obvious that the bibliography, valuable in its proper sphere, cannot replace "objective" subject cataloging as a finding device. This is true because the bibliography is a functional tool, and it is most efficiently utilized in conjunction with a job of research from a particular vantage point, as the research is proceeding. The bibliography as a method can never fully open up a library of pamphlets, however restricted, because the points of view of research are infinite. Objective subject its pamphlets available through these channels: diverse subjects, shelf arrangement, shelflist, author, and an indirect approach to title. It is an inexpensive technique by almost any standard.

A. Pamphlets are classed rather broadly (for this library) by divisions in the regular classification scheme used for books, in this case the Library of Congress classification. In any specific grouping, each pamphlet is marked with the same class and cutter numbers, for example:

HE108I (indicating pamphlet material on the subject of government ownership of $Z_{p} \quad$ railroads in the United States. The cutter mark $Z_{p}$ puts the pamphlets at the end of the particular grouping; the p separates pamphlets from other $Z$ cutterings.)

cataloging has plenty of faults (subject headings must always be outdated and annoying to the specialist so long as reliance is placed on laboriously establishing their authenticity and laboriously changing them when usage has already moved on) and it cannot perform the task with full competence, but it is on the whole a much more adequate method since it looks at materials from broadly convergent and uniform points of view, decided upon in advance.

\section{Solution of Treatment}

It is clearly encumbent upon the research librarian to devise some solution for the treatment of ephemera other than that of unsupplemented physical arrangement: a method which offers not merely one "simple" path to its subject matter but as many diverse approaches as is economically feasible. This method should arrive at a balance between the relative value of the individual pamphlet in the context of other library resources and the total costs of acquiring, processing, storing, and servicing.

The technique employed at Stanford in the Hopkins Transportation Library makes
B. Pamphlets are housed in containers which will obviate the usual physical diffculties and which will serve as unit receptacles for the class groupings. If there are only a few items in a particular grouping, they are placed in a boarded manila envelope until the class grows larger. They are then transferred to a closed pamphlet box bearing the same broad number. The envelope may be used over again. If space considerations are not paramount, the pamphlet box may be used from the first. If the box in turn becomes full, a decision is made whether to bind this grouping or to extend its alphabet into a second box. The decision does not affect the indexing records.

Pamphlets are arranged and stored in this fashion because the juxtaposition to other allied materials in the classification is an important reference factor and because employing the regular shelving in lieu of specially manufactured receptacles, such as vertical files, usually saves space and expense.

C. Pamphlets are recorded and indexed in the following steps:

r. The shelflist card represents a par- 
ticular class grouping and may be considered the main card. It is a unit card and its face looks like this: ars but for their own procedural ease in checking references and acquisition lists for holdings.

HEI08I [Pamphlet material on the subject of government ownership of railroads in $\mathrm{Zp}$ the U.S.]

2. The verso of the shelflist card records the authors (or titles where there are no authors) of the pamphlets in this grouping and the subject headings which develop from these pamphlets. It traces the author (briefly) and the subject cards which are made from it :
3. These cards are filed in the union cata$\log$ of transportation materials.

D. The economies which accrue from this technique may be designated as follows:

I. Subject cards are originally made because of specific pamphlets, but are not tied to them, and instead represent the entire

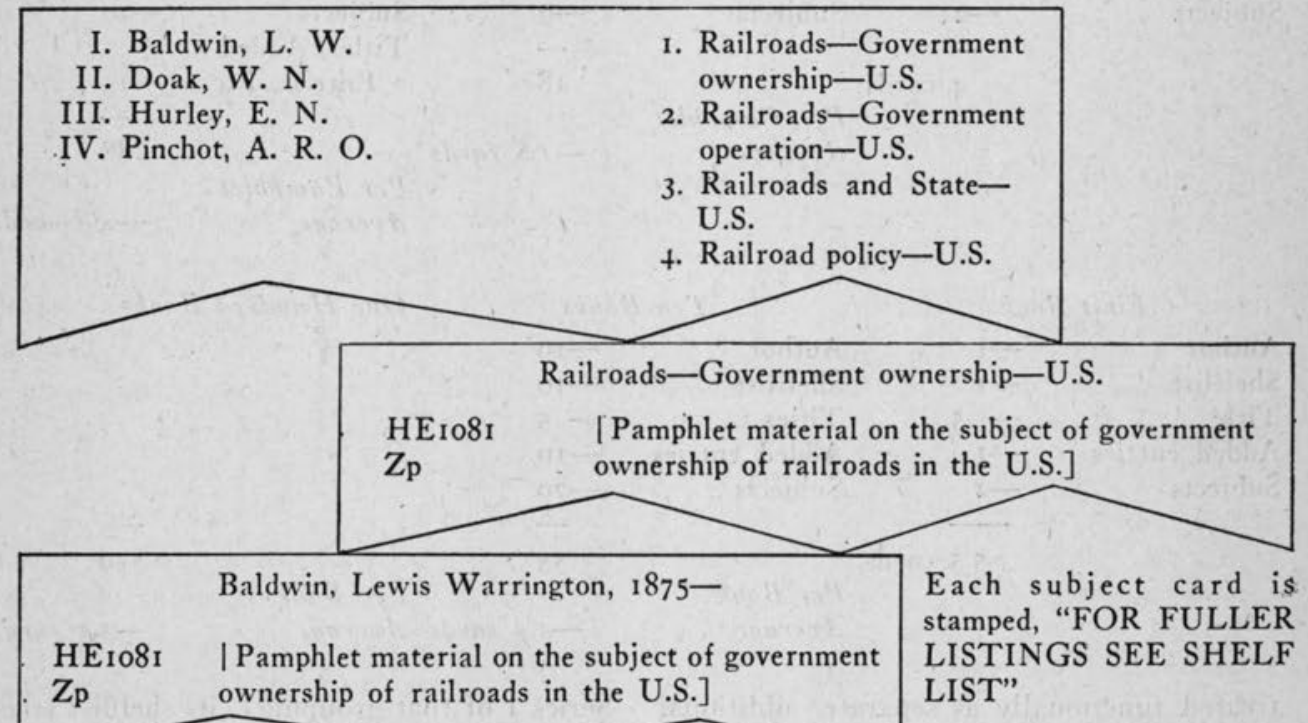

The reverse of each author card shows the titles in this grouping written by the author. Pagination and date, together with title, identify specific ramphlets in the great majority of cases. Librarians working with pamphlets come to realize that such identification is important not only for the convenience of schol- class grouping. As pamphlets are added to a class number, subject cards accrue until the grouping is focused by a ring of applicable subject headings. Also, as the number of pamphlets increases, each heading serves a more diffuse purpose, in proportionately

Government ownership of the railroads.

(1924, Iop.)

How can the government operate the railroads?

(1926, 21p.)

What public ownership really means.

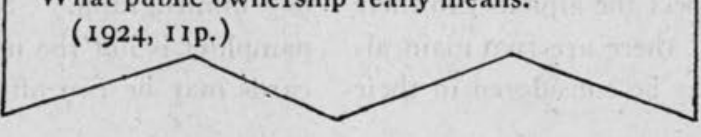


increasing utility.

2. Author cards are prepared, not for each title, but for each class grouping. Once made, a specific author card reports automatically any subsequent pamphlet acquisition of this author in the grouping. (Added entries and title cards are not a usual feature of the system at the Hopkins library. However, such entries may be handling. (I) Considerable space may be left between tracings on the reverse of the shelflist and author cards. New authors and titles may then be intertyped on their respective lists. (2) Tracings may be added as they appear, without regard to alphabetizing. If it is decided, finally, to bind the contents of a certain pamphlet box or group of boxes in a class number (as

\section{First Pamphlet}

Shelflist
Author
Subjects

First Book

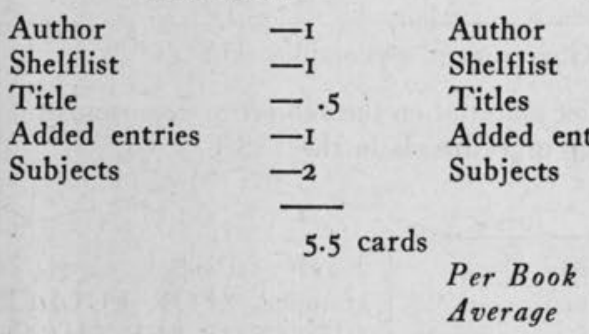

treated functionally as separate, additional "authors" in this scheme, without altering any of its other features.)

3. Shelflist cards summarize their authors on their reverse sides, and the respective author cards summarize their titles, thereby providing convenient bibliographical listings and proper tracing mechanism. If a large collection of pamphlets is cataloged in one operation, as is being done at Stanford, it is possible to arrange these listings in alphabetical order. Current additions, however, do not respect the alphabet in their order of arrival and there are two main alternatives which may be considered in their

\section{One Hundred Pamphlets in One Grouping}

$\begin{array}{lc}\text { Shelflist } & -\mathrm{I} \\ \text { Authors } & -52 \\ \text { Subjects } & -20 \\ \text { Titles, Added } \\ \quad \text { Entries, Etc. } & -15 \\ & \frac{-15}{88} \\ \begin{array}{ll}\text { Per Pamphlet } \\ \text { Average }\end{array} & -.88 \text { cards }\end{array}$

One Hundred Books
Ten Books

$$
\begin{aligned}
& -10 \\
& -10 \\
& -5 \\
& -10 \\
& -20
\end{aligned}
$$

$\begin{array}{lll}\overline{55} & \overline{550} \\ -5.5 \text { cards } & \begin{array}{l}\text { Per Book } \\ \text { Average }\end{array} & -5.5 \text { cards }\end{array}$

Series I of that grouping), its shelflist tracings and its author card tracings for that class number may then be conveniently alphabetized and retyped. The second alternative is followed at the Hopkins library, since no great inconvenience is felt by its users and since the first method is wasteful of card space and eventually ends in the same dilemna which it attempts to contravert.

4. The shelflist card is a unit card and may be reproduced cheaply by hectograph or mimeograph. Since the individual pamphlet is not the unit, a large number of cards may be run off at one time for prob- 
able future increases in each class grouping. The mimeograph master may even be stored if it is felt desirable. ${ }^{12}$

5. The flexibility of the system is such that any number of desired deviations may be made without interference with its basic principles. At Stanford, for instance, pamphlets of relative insignificance for research purposes are merely assigned class numbers and filed in their appropriate containers. No author listing is made (unless one exists by virtue of another previously handled item) and no title tracing is made on the author card, if it exists. The approaches to these pamphlets are therefore by subject headings and classification only. If it is not considered that their value has been augmented by the passage of time, they are

\footnotetext{
12 It should be emphasized that L.C. cards have no functional place in this system. The economies which accompany pamphlet cataloging from the shelflist as main card are lost when the author unit card enters the main card are lost when the author unit card enters the
picture. This is not to say that the informational content of the L.C. card cannot be utilized in establishing the entry and selecting subject headings.
}

discarded ultimately when the class grouping is reviewed for binding. No records need be destroyed, since none were prepared for these pamphlets as individual units.

6. An increasing economy is effected as the pamphlet collection develops. Subject headings soon "saturate" a class grouping until, after a certain point, few additions are required in that category. Authors who write pamphlets are often prolific in the medium and in their particular subjects, and their entries, once established, need not be repeated. A more exact understanding of the relative costs involved in cataloging a pamphlet in this fashion can be arrived at by comparing the number of cards required with those required in the cataloging of books, which is shown on page 420 . (These averages are random samples taken from the Hopkins Transportation Library catalog; they are rough intentionally, for illustrative purposes.)

\section{Comments}

\section{(Continued from page 404)}

tion is, therefore, not one that can be settled without reference to size and to local interpretations of method. For each institution the matter of segregation will be more determined by the local situation, including size, than by any other consideration.

Experimentation which seeks to improve instruction or library service to large groups may be helpful, but there is no consensus of educational thinking to indicate a final method. Meanwhile, it will not be mark- ing time to reaffirm our faith in the individual character of education, the association of student with teacher and of student with book. Each of us must seek the practical way of making library materials convenient and useful to him. To this end we cannot give too much attention to the selection of library personnel. Our employees must be the most responsive that we can find. The success of our libraries is an aggregate of individualized personal service. 